\section{Formação da comunidade científica no Brasil}

Por Sirnon Schwartzman. São Paulo, Companhia Editora Nacional e Finep, 1979. XIX, $481 p$.

O trabalho realizado por Simon Schwartzman à frente de equipe

de pesquisadores, com o apoio fiinanceiro da Finep, constitui marco de importância nos estudos que presentemente manifestam preocupação com o desenvolvimento científico e tecnológico em nosso país, bem como com as repercussões e o relacionamento que a ciência, a tecnologia e a comunidade científica manteriam com a sociedade, com o Estado e com a utilização do conhecimento científico pela sociedade. Nas palavras do próprio autor, "'É 'este entendimento da ciência como atividade dotada de uma tradição e método próprios, ao mesmo tempo influida e influindo sobre sua época histórica, que caracteriza, se não os resultados, pelo menos as intenções deste estudo" (p. 7)

O trabalho, no seu conjunto de cunho claramente histórico, procura apresentar ao leitor dados e fatos que o auxiliem na ordenação e acumulação de conhecimentos a respeito das atividades científicas e, em época mais recente, também tecnológicas, em nosso país. O livro não se dedica, por opc̣ão de seu autor, à reflexão da problemática cientifica e tecnológica em contexto social e político.
Dentro dos limites a que se propôs, o trabalho parece satisfatório. Ao lado de documentos e textos anteriores, dedicados ao estudo do tópico, há ainda a inteligente opção metodológica de utilizar entrevistas, na aparência abertas e não-estruturadas, com membros destacados da comunidade científica brasileira. Exemplo de tal procedimento e encontrado nos depoimentos colhidos em entrevistas com Paulo Duarte, para ilustrar a gênese e organização da Universidade de São Paulo (p. 191-214).

O texto contém 10 capítulos e 2 apêndices, um contendo a cronologia da ciência brasileira e outro, as notas biográficas sobre os entrevistados, em número de 66 . Os capítulos 2 e 3 cobrem o período colonial e imperial. Quando se trata. do período colonial e mesmo do Primeiro Império, é impossivel separar a cultura brasileira da portuguesa. Assim, o autor constata que, em matéria científica, como de resto em outros campos, Portugal se posiciona fora das principais tendências européias. O país que deu mostras de inovação e liderança tecnológica no final da ldade Média e no início dos tempos modernos, com suas realizações no campo da tecnologia naval, o que não seria possível nem inteligivel sem uma orientação científica e empírica do conhecimento que transcendesse, portanto, a orientação escolástica, acaba por recusar o Renascimento, repudiar o empirismo científico e enclausurar-se no escolasticismo dos comentadores. O grande debate científico e filosófico que ocupou os séculos XVI, XVII e XVIII não contou com a participação de Portugal, cuja cultura, filosofia e educação foram estreitamente supervisionados e controlados pelos jesuitas. O Marquês de Pombal seria responsável pela grande ruptura, pondo término à hegemonia jesuítica em matéria cultural. Todavia, o tempo transcorrido era irrecuperável e os grandes modelos universitários, bem como o racionalismo, o emprirismo e o liluminismo europeus, nunca chegariam àquele país. A universidade portuguesa manteve-se estreitamente ligada à escolástica e, no Brasil, educação era sinônimo de instrucão eclesiástica. Só no inicio do século XIX, com a transferência da Corte de D. João VI para o Rio de Janeiro, é que instituições leigas voltadas à ciência se criam entre nós.

A engenharia e a medicina surgem ligadas às necessidades das. Forças Armadas Regulares (Exército e Marinha). A Escola de Minas de Ouro Preto, criada em 1875, é mais exceção do que norma no contexto centralizador de nossa educação e com relação à tendência colonial e imperial de ter no Rio de Janeiro quase que toda a atividade científica. Além disso, conviria mencionar os museus (Museu Nacional, Jardim Botânicol; já no século $X X$, a tradição naturalista prossegue com a criação do Museu Paulista e do Museu Paraense. Não deve ser esquecido no Segundo Império o papel importante, nem sempre, infelizmente, conveniente aos interesses do desenvolvimento científico, do nosso segundo imperador. O seu perfil de homem de cultura, aliado ao centralismo da administração imperial, fizeram com que D. Pedro II muito se interessasse pela gestão das instituições científicas imperiais, nela intervindo com freqüência.

Nos capitulos 4 e 5, são descritos os episódios que consolidam algumas linhas de pesquisa e que manifestam claro compromisso com a aplicabilidade científica. $\mathrm{Na}$ linha biológica, o elemento desencadeador é a preocupação com problemas de saúde pública. É assim que o Instituto de Manguinhos se forma, se consolida e adquire repercussão, não só nacional, mas mesmo internacional. O debelar da febre amarela no Rio de Janeiro e a vacinação antivariólica, ambos eventos que tiveram lugar no início de nosso século, foram os responsáveis pelo apoio decidido do Governo federal à ciência aplicada. Em São Paulo, temos o aparecimento do instituto Adolfo Lutz e do Instituto Soroterápico, depois Butantã, organizações paulistas criadas igualmente para atender e solucionar graves problemas de saúde pública que assolavam o estado.

Fato a ressaltar é que a primeira universidade brasileira só surgiu na década de 1930, e as escolas tradicionais, voltadas ao ensino supe- 
rior Imedicina, direito, engenharia), eram instituições sem tradição ou respeitabilidade científica e desprovidas de qualquer atividade de pesquisa. Assim sendo, o interessado em estudar ciência e envolver-se em pesquisa científica deveria buscar instituições não-escolares, caso dos institutos mencionados e dos museus. A documentação e os relatos sobre o ensino nas escolas tradicionais indicam uma tradição escolar caricatural, baseada em aulas expositivas de sabor "catedratical", ministradas por professores que pouco conheciam além do manual ou "tratado" em que apoiavam sua docência, e sem qualquer capacidade e familiaridade com a pesquisa. Eram profissionais certamente bem-sucedidos, mas cujo comparecimento à escola tinha o fito exclusivo de dar aulas, pois muito tempo se passou até que o regime de trabalho em tempo integral fosse aceito pelas autoridades como desejável e necessário.

A dificuldade em desenvolver a pesquisa em uma comunidade científica na universidade é analisada como decorrência da adoção de modelos universitários equivocados. Já vimos que a tradição lusa nada tinha a fornecer de criativo, a mesmo acorrendo com o modelo francês que depois se tentou para cá transferir. A universidade francesa tornou-se um "museu cultural e científico" depois de Napoleão, indo a ciência francesa abrigar-se em instituições para universitários, entre elas as grandes écoles. O Centre Nationale de la Recherche Scientifique - CNRS aparece muito depois, a fim de reativar uma comunidade científica desarticulada e letárgica. O mode- lo europeu fecundo e que foi capaz de unir ensino e pesquisa foi a universidade alemã, que os norte-americanos imitaram criando, junto a suas universidades voltadas ao ensino, as graduate schools destinadas ao aprendizado em nivel de pós-graduaçăo e à pesquisa.

As décadas de 1920 e 1930 assistem a grandes transformações de nossa sociedade e conseqüentemente ao reposicionamento da problemática científica. O país começa a industrializar-se num ritmo mais acelerado e aumenta, também, o crescimento urbano, trazendo ao cenário nacional um centro econômico e cultural alternativo que é São Paulo. Até então, - Rio de Janeiro aparecia como o ponto de convergência indiscutivel da ciência brasileira. A industrialização paulista, ao transformar a estrutura ocupacional da sociedade, exerce pressões em prol da mudança educacional, repercutindo de modo direto sobre o papel da ciência.

Além destas mudanças do sistema educacional, o mundo industrial nascente já é suficiente para despertar o problema e as necessidades ligadas à tecnologia. É em meio a este clima, e com o início da Segunda República que em breve desaguaria no Estado Novo, que se desenvolve o debate em busca de alternativas educacionais, culturais e, portanto, científicas. O positivismo, que estendeu sua influência até os princípios da Segunda República, teve efeito danoso para o desenvolvimento científico de nosso país. "Derrotado intelectualmente, na área estritamente científica, o positivismo continua por várias décadas do período republicano como idéia-força de engenheiros, técnicos e intelectuais, que identificam, na organização de um Estado forte e centralizador e no pragmatismo da técnica - uma técnica, em geral, mal dirigida - a forma de realização de seus ideais" (p. 189).

Na época, os dois acontecimentos de maior importância são a criação da Universidade do Distrito Federal - UDF e da Universidade de São Paulo - USP, sendo que esta transcendeu em importância à primeira. A USP contou com o decidido fascínio de seus fundadores pela cultura francesa em primeiro lugar, e dos demais países europeus Icom exceção da Grã-Bretanhal, em segundo. A nova universidade, à semelhança da francesa, ou de como seus fundadores e idealizadores entendiam a universıdade francesa, estaria norteada de forma primordial para a especułação, vindo em segundo plano as escolas tradicionais (direito, politécnica e medicinal, chamadas, não sem menosprezo, de "profissionalizantes". O centro da univer- sidade e o seu elemento propulsor era a Faculdade de Filosofia, Ciências e Letras. É elucidativo o depoimento feito por Paulo Duarte em entrevistas com pesquisadores: "Nós elegemos - aí já fizemos de comum acordo - dois paradig mas, digamos assim, para a Universidade. Em primeiro lugar, tanto a formação do Julinho (Júlio de Mesquita Filhol como a minha são formações francesas. Mas nós não quisemos nos restringir à nossa formação francesa. Escolhemos a Sorbonne, evidentemente, para estudar uma universidade cientificamente estruturada. E escoihemos também a universidade inglesa, através de Cambridge. Mandamos buscar tudo quanto fosse informação dessas universidades. Mas, na realidade, a organização francesa era superior à inglesa... lo grifo é nosso). E a nossa organização, pode-se dizer que em $80 \%$, seguiu o modelo francês. (...) a Universidade francesa tinha como celula mater a Faculdade de Filosofia, Ciências e Letras" (p. 197)

A Universidade de São Paulo e, em particular, a sua Faculdade de Filosofia, Ciências e Letras, contaram com a participação de professores franceses (sociologia, filosofia, antropologia, história, literatura francesa, geografia, psicologia): italianos (matemática, física, mineralogia); alemães (química, botânica e zoologia) e portuguese's e espanhóis em suas respectivas linguas e literaturas. A relação de professores que aqui estiveram, alguns por longos periodos, inclui nomes destacados, cuja vinda para - Brasil foi, em muito, apressada pela instabilidade que varria a Europa na década de 1930 . Isto contribuiu para que a Faculdade de Filosofia, Ciências e Letras da USP se tornasse o mais importante centro científico que se constituira no Brasil desde o momento de sua fundação. Isto não exclui críticas que possam ser feitas ao modelo adotado, bem como à sua implantação. Todavia, a Faculdade de Filoșofia, Ciências e Letras da USP foi um ponto onde se processou a tránsferência de conhecimentos. então atualissimos, onde se desenvolveu integração entre ensino e pesquisa, e, muito particularmente, onde os professores europeus formaram, com alguns de seus alu- 
nos brasileiros, uma comunidacie de cientistas e scholars que até hoje é atuante em nosso meio.

De fundamental importância na evolução da comunidade científica e da ciência no Brasil foi a criação da USP e da UDF, que permitiram a profissionalização do cientista nos termos em que hoje o entendemos. Lembra ainda o texto de Simon Schwartzman que, a partir de então, a comunidade brasileira desenvolve laços e interação regu lares com a comunidade científica internacional. "Expor seu trabaiho à comunidade internacional, através de publicação em revistas estrangeiras e viagens de especialização para o exterior, passou a fazer parte rotineira do universo do novo cientista brasileiro. O grupo de referência deixou de ser a comunidade científica local, para ser a internacional" (p. 224)

Muito importante também para a profissionalização cientifica fơi o esquema financeiro que se criou para viabilizá-la. Ao nível da universidade, lança-se a idéia do tempo integral, que se inicia timidamente, mas ganha volume com o passar dos anos. Grande vitória para a comunidade científica foi obtida em 1951, com a criação do Conselho Nacional de Pesquisas - CNPq, bem como com a criação da Coordenação do Aperfeiçoamento do Pessoal do Ensino Superior - Capes e da Fundação de Amparo à Pesquisa do Estado de São Paulo - Fapesp em 1960. A mobilização da já ponderável comunidade científica manifestou-se de forma clara em 1948, com a criação da Sociedade Brasileira para O Progresso da Ciência SBPC.

O pós-guerra assistiu a uma grande efervescência científica no mundo todo e também no Brasil. A energia nuclear e a relação mais imediatamente perceptivel entre a ciência e suas aplicações levaram a que se buscasse a expansão e a definitiva institucionalização da comunidade científica, com o apoio è o envolvimento diretos do Estado. Não se pode negar que o impacto mundial criado pela missão nuclear conferiu à física posição científica destacada e corrseqüente capacidade de atrair verbas e talentos, do qual são bom exemplo o Instituto de Biofísica, o Instituto de Eletrotécnica da USP, o Instituto de Energia Atômica da USP, o Instituto de Física Gleb Wataghin na Unicamp, o Instituto de Física Teórica, o Instituto de Pesquisa Radioativas e o Centro Brasileiro de Pesquisas Físicas.

Além da física, duas outras linhas de desenvolvimento científico se firmam: são a genética e a química.

Finalmente, ao término da década de 1960, uma nova etapa tem lugar em nosso mundo científico, com o envolvimento direto e direcionado do Governo federal no mundo da produção científica, na medida em que ela é vista como de importância decisiva para diminuir a nossa dependência tecnológica e, também, como manifestação de poder nacional. Por certo, os motivos que levaram ao envolvimento do BNDE, por intermédıo do Fundo de Desenvolvimento Técnico e Científico - Funtec e posteriormente do Fundo de Financiamento de Estudos de Projetos e Programas de Desenvolvimento - Finep, foram inteiramente diversos dos da ciência especulativa. A preeminência pertencia à aplicabilidade científica e o que se pretendia era diminuir a lacuna tecnológica, bem .como abordar tópicos cuja importância fora decidida politicamente, como atestam os dois Planos Básicos de Desenvolvimento Científico e Tecnológico - PBDCT aprovados e executados até o momento.

O trabalho resenhado é uma indiscutivel e meritória contribuição à historiografia da comunidade científica brasileira e, como tal, deve ser não somente apreciado, mas utilizado como proveitoso instrumento para pesquisas e estudos futuros que certamente se seguirão. O estudo da ciência e da comunidade científica na chamada periferia é ainda escasso e os seus resultados podem ser interessantes para o entendimento do próprio desenvolvimento cientifico.

O trabalho trata perfunctoriamente de temas delicados e por certo nebulosos como o das relações entre ciência e tecnologia e ciência e sistema educacional, bem como das vinculações entre ciência e sistema produtivo e da mais crucial das relações nas sociedades modernas, que é a da comunidade científica e da ciência com o Estado. O "tripé" norteamericano lempresa privada-Estado-universidadel, que, não deixou de influenciar o nosso atual sistema de ciência e tecnologia, com todos os órgãos governamentais que o compõem (FBDCT, Finep. CNPq e Capesi, não pode, todavia ser replicado no Brasil. Aparentemente a perna mais curta no tripe e que torna o sistema coxo é o nosso sistema produtivo, que tem condições precárias de participar do esforço. A ação do Estado, no Brasil, vem sendo de apoio ao estorço científico, mas não de forma clara e inambígua. Se é fato que os anos recentes assistiram ao empenho e até mesmo à iniciativa do Estado de promover o desenvolvimento científico, sempre numa perspectiva de avanço tecnológico, cumpre ressaltar que isto não constitui a história em sua inteireza. Sob outros aspectos o Estado reagiu de modo lento, e por vezes nem mesmo reagiu, a demandas da comunidade científica. A epopéia do regime de trabalho na universidade brasileira, inclusive no sistema universitário federal, ainda é inconclusa e não é dos meIhores exemplos de ação do Estado.

Ainda no contexto da ambigüidade no relacionamento entre 0 Estado e a comunidade científica, incomoda o silêncio completo sobre a repressão levada a efeito no período 1964-1977, o qual foi particularmente realçado após a promulgação do Ál-5. A repressão atingiu com dureza a comunidade científica brasileira, afastando muitos cientistas de seus cargos e levando dezenas deles ao exílio invoJuntário. Não acredito que a impor tância de tal fato pudesse ser deixada de lado, num trabalho como o de Simon Schwartzman. Que estes reparos não servem, nem remotamente, para diminuir a seriedade e o mérito da obra, é desnecessário repetir.

Carlos Osmar Bertero 